\title{
Use of mutants to dissect the role of ethylene signalling in organ senescence and the regulation of yield in Arabidopsis thaliana
}

Article

Accepted Version

Bennett, E. J., Roberts, J. A. and Wagstaff, C. (2014) Use of mutants to dissect the role of ethylene signalling in organ senescence and the regulation of yield in Arabidopsis thaliana. Journal of Plant Growth Regulation, 33 (1). pp. 56-65. ISSN 0721-7595 doi: https://doi.org/10.1007/s00344-013-9382-0 Available at https://centaur.reading.ac.uk/37434/

It is advisable to refer to the publisher's version if you intend to cite from the work. See Guidance on citing.

To link to this article DOI: http://dx.doi.org/10.1007/s00344-013-9382-0

Publisher: Springer

All outputs in CentAUR are protected by Intellectual Property Rights law, including copyright law. Copyright and IPR is retained by the creators or other copyright holders. Terms and conditions for use of this material are defined in the End User Agreement. 


\section{CentAUR}

Central Archive at the University of Reading

Reading's research outputs online 
Use of mutants to dissect the role of ethylene signalling in organ senescence and the regulation of yield in Arabidopsis thaliana

Running title: Ethylene signalling and senescence in Arabidopsis

Emma J Bennett ${ }^{1}$, Jeremy A. Roberts ${ }^{2}$ and Carol Wagstaff ${ }^{1 *}$

${ }^{1}$ Department of Food and Nutritional Sciences and Centre for Food Security, University of Reading, PO Box 226, Whiteknights, Reading, RG6 6AP.

${ }^{2}$ Plant and Crop Sciences Division, School of Biosciences, The University of Nottingham, Sutton Bonington Campus, Loughborough, Leicestershire, United Kingdom. LE12 5RD.

\section{*Corresponding author:}

Dr Carol Wagstaff

Department of Food and Nutritional Sciences, University of Reading, PO Box 226,

Whiteknights, Reading, RG6 6AP

Phone: +44(0)118378 5362

Fax: $+44(0) 118$

e-mail: c.wagstaff@ reading.ac.uk 


\begin{abstract}
The role of ethylene in regulating organ senescence in Arabidopsis has been investigated by studying the development of mutants that have an attenuated capacity to perceive the gas. The onset of leaf senescence and floral organ abscission was delayed in the ethylene insensitive mutant etrl. The photosynthetic life span of rosette leaves was similarly extended in the gain of function mutant ers 2 and this mutant also exhibited a delay in the timing of pod dehiscence primarily as a consequence of an extension in the final stages of senescence. A detailed analysis of yield revealed that whilst thousand grain weight was increased, by as much as $20 \%$, in etr 1 , ein 4 and the loss of function mutant etr2, only the latter showed a significant increase in total weight of seeds produced per plant. The other mutants studied exhibited a reduction in total seed yield of almost $40 \%$. These observations are discussed in the context of the possible role of ethylene in regulating organ senescence and their significance in the breeding of crop plants with enhanced phenotypic characteristics.
\end{abstract}

\title{
Keywords:
}

Ethylene signalling, mutant, senescence, abscission, Arabidopsis, yield, seed, pod development, dehiscence 


\section{Introduction}

Since its serendipitous discovery over one hundred years ago ethylene has been known to regulate plant growth and development (Neljubov 1901), however, it was not until 1934 that it was officially classified as a plant hormone. This gaseous hydrocarbon is synthesized by most, if not all, plant tissues and affects a wide variety of processes including: germination, seedling growth, organ senescence, abscission, fruit ripening, grain filling, and responses to biotic and abiotic stresses (Abeles and others 1992; Gao and others 2003; Yang and others 2006; Robert and others 2008; Carbonell-Bejerano and others 2011).

Ethylene is only one of many factors affecting organ senescence, a process which also requires the plant to be at an appropriate stage of developmental competency to respond to the gas. For instance, young leaves fail to undergo senescence even when exposed to concentrations of ethylene that are known to promote the process in mature tissues (Hensel and others 1993; Grbić and Bleecker 1995; Buchanan-Wollaston 1997; Jing and others 2005) and these observations have given rise to the concept of a 'senescence window' in plant development (Jing and others 2002). The presence of reproductive structures, which constitute a resource sink in the plant, has also been shown to affect both the onset and/or rate of leaf senescence (Bennett and others 2012).

In Arabidopsis ethylene is perceived by a suite of receptors (ETR1, ETR2, ERS1, ERS2 and EIN4 - Chang and others 1993; Hua and others 1995; Sakai and others 1998) which are homologous to bacteria two-component histidine kinase (HK) sensors (Binder and others 2012) and predominantly located on the endoplasmic reticulum (ER). Based on their phylogeny and structure the ethylene receptors can be split into two subfamilies with ETR1 and ERS1 constituting subfamily I, whilst ETR2, EIN4 and ERS2 form subfamily II. The major difference between these groups is that the His kinase domain of subfamily II lacks any catalytic activity (Guo and Ecker 2004). Although it has been concluded that HK activity is not necessary for receptor signalling and therefore the subfamily II receptors are still able to inhibit ethylene responses (Hall and others 2012). The receptors act as negative regulators of ethylene signalling and in their unbound state they activate the Ser/Thr kinase CTR1, which leads to a suppression of the downstream ethylene signalling component EIN2 (Bleecker and Kende 2000). When ethylene binds to the receptors, with the aid of a copper cofactor provided by the copper transporter RAN1 (Rodriguez and others 1999; Binder and others 2010), this prevents the receptors from signalling, thereby releasing the repression of the 
EIN2 pathway and enabling ethylene responses to occur. Consequentially mutations affecting the ability of a receptor to bind ethylene can lead to a dominant insensitivity to the gas (Chang and others 1993; Hua and others 1995; Sakai and others 1998).

In recent years, advances in ethylene research have rendered the concept of a linear signalling pathway somewhat oversimplified and despite the ethylene receptors being genetically similar and all contributing to the ethylene signalling pathway, it is emerging that they are not functionally redundant and are not able to fully compensate for one another (O'Malley and others 2005). For example ETR1 has a distinctly different role compared to the other receptor isoforms in ethylene-stimulated nutational bending of Arabidopsis hypocotyls (Binder and others 2006). Instead they act in a synergistic manner to enhance receptor output and are capable of interacting with either each other, or CTR1, to form homodimers and larger complexes ( Gamble and others 2002; Gao and others 2003; Gao and others 2008; Grefen and others 2008; Liu and Wen 2012). Within this system it is believed that the subfamily I receptors play a more central role in the ethylene signalling pathway $(\mathrm{Qu}$ and others 2007, Gao and others 2008). This is possibly due to subfamily I having a stronger association with CTR1 and it has been proposed that a degree of subfamily II receptor signalling relies upon the presence of subfamily I receptors (Cancel and Larsen 2002; Qu and others 2007) . Interestingly the receptors are also capable of directly interacting with EIN2 (Bisson and Groth 2010). The emerging number of potential receptor interactions could help explain why plants are able to respond differently to such a vast range of ethylene concentrations across diverse tissue types (Liu and Wen 2012, Shakeel and others 2013). Equally it is also possible that they are able to signal down CTR1 independent pathways (Desikan and others 2005; Ju and Chang 2012; Shakeel and others 2013) to bring about a diverse array of responses. The need for multiple receptors is highlighted by the fact that in all plants studied to date more than one ethylene receptor has been identified (Binder and others 2012). In addition the ethylene signalling system in Arabidopsis shares a great deal of similarity with crop plants such as tomato, rice and maize ( Gallie and Young 2004; Klee 2004; Wuriyanghan and others 2009), making it easier to translate research from a model plant into commercially important crops.

As the structure and function of the ethylene receptors begins to be unravelled it is becoming increasingly clear that their role in plant development, and specifically organ senescence, has yet to be fully elucidated. It has been predicted that delaying the start of senescence by just 2 days could lead to an $11 \%$ increase in the carbon contributed to the plant from a leaf (Thomas and Howarth 2000), which if harnessed correctly could lead to 
yield increases. For example decreased expression of the ethylene receptor ETR 2 in rice increased thousand grain weight by up to $4 \%$ due to an alteration of starch and sugar accumulation in the filling grain (Wuriyanghan and others 2009). In addition postponing the onset of senescence is also crucial for delaying postharvest degradation and extending shelf life. One way of achieving this is to block the ethylene receptors so they are no longer capable of sensing ethylene and the pathway remains repressed. Commercially this has been achieved by the application of 1-methylcyclopropene (1-MCP) (Sisler and Serek 1997), which is highly effective in bagged leaves such as basil not only in terms of delaying senescence but also extending shelf life and retaining quality (Hassan and Mahfouz 2010). Whilst successful, 1-MCP application only provides a short term solution and requires a direct intervention to apply the chemical, therefore a more permanent solution could involve reducing the receptors sensitivity to ethylene perception (Agarwal and others 2012). By controlling receptor expression Gallie (2010) demonstrated that it was possible to control temporally the extent of the ethylene response. To date most research has focused upon ETR1 as it was the first receptor to be isolated and characterised (Bleecker and others 1988) and the dominant ethylene insensitive mutant $e t r l-1$ has been shown to delay the onset of leaf senescence and consequentially extend leaf lifespan by approximately 30\% (Grbić and Bleecker 1995). An ethylene insensitive phenotype of coriander has been generated by transforming the plant with a mutated version of ERS1 and this was found to delay significantly leaf and flower senescence (Wang and Kumar 2004). Similarity wheat W-erl may be involved in leaf senescence (Ma and Wang 2003).

Whist the much research effort has focused on the role of ethylene in flower development and climacteric fruit ripening (Serek and others 2006; Agarwal and others 2012) less attention has been given to its impact on crop quality and yield. Given that siliques share similar characteristics with climacteric fruit (Kou and others 2012) and that ethylene is believed to have a central role in pod senescence (Wagstaff and others 2009) the work described in this paper focuses on enhancing our understanding of the role of ethylene perception and signalling in Arabidopsis leaf, flower and fruit senescence and the impact of this on seed yield. To help us dissect the role of ethylene signalling we have utilised receptor mutants that exhibit either a gain (etr1, ein 4 , ers 2$)$ or a loss (etr2, ers 1$)$ of function to the gas. 


\section{Materials and Methods}

\section{Plant material and growth conditions}

Arabidopsis (Arabidopsis thaliana) ethylene receptor mutants ein4 (NASC ID: N8053), ers1 (NASC ID: N3978), ers2 (NASC ID: N8854), etrl (NASC ID: N237) and etr2 (NASC ID: N657634) plus the background ecotypes they originated from, Columbia (Col-0), Noosen (No) (NASC ID: N3081) and Wassilewskija (Ws) (NASC ID: N22659) were obtained from The European Arabidopsis Stock Centre (NASC; Nottingham, UK; http://arabidopsis.info/). All plants underwent a $4^{\circ} \mathrm{C}$ stratification cold treatment for 2-3 days before being transferred into a Fitotron plant growth chamber (Weiss Gallenkamp) set to $20^{\circ} \mathrm{C}, 55 \%$ relative humidity with a photon flux density of $200 \mu \mathrm{mol} \mathrm{cm} \mathrm{s}^{-2}$ and $16 \mathrm{~h}$ photoperiod. Plants were grown in individual 90mm diameter pots containing horticultural potting medium (William Sinclair).

\section{Leaf senescence measurements}

Plants were harvested at set intervals after the date leaf 6 was tagged and aerial images taken, subsequently leaf 6 was removed from the plant and immediately frozen in liquid nitrogen for chlorophyll $a$ and $b$ analysis. Chlorophylls were extracted from frozen rosette leaf material, leaf 6, using N,N-dimethylformamide and left for 7 days in the dark at $4^{\circ} \mathrm{C}$. The sample absorbance was measured at $\mathrm{A}_{664}, \mathrm{~A}_{647}$ and $\mathrm{A}_{480} \mathrm{~nm}$ using a plate reader (Spectra max 340 PC) and the chlorophyll $a$ and $b$ concentrations were calculated using the coefficients of Wellburn (1994).

\section{Time course measurements}

The time taken for pods on the primary inflorescence to develop was visually scored based upon the following scale (Wagstaff and others 2009), flower anthesis: flowers fully open, petal abscission: petals begun to abscise, pod stage 1: pods are green and fully mature, pod stage 2: pods are $50 \%$ yellow, pod stage 3: pods are $100 \%$ yellow, pods stage 4 : pods are brown and just about to dehisce, pod shatter: pod opened to release some seeds. The total plant lifespan is a measure of the time taken for the plant to go from bolting to the end of flowering.

\section{Physiological measurements}

Seed physiological measurements were taken from pods at different stages of development; the numbers of seeds per pod and seed weight per pod were obtained from stage 4 pods 
which were fully senescent and about to dehisce. Whereas pod length and area were determined from stage 2 pods which were visually scored as being $50 \%$ yellow. Pod area and the number of seeds per pod were established using Image J (NIH Image). For the seed weight per pod and thousand grain weight (TGW) all seeds were oven dried (GENLAB) at $70^{\circ} \mathrm{C}$ until they reached a constant weight. Total seed yield was determined by weighing the seeds collected from plants grown in aracons which had become fully senescent and reached the end of their life span. The TGW was calculated by taking 100 seeds from the total seed yield experiment, drying them until they reached a constant weight and multiplying this figure by 10 to represent 1000 seeds. The number of pods per plant, height of the primary inflorescence, number of rosette leaves and number of axillary stems were all measured when pod shatter on the primary inflorescence began.

\section{Statistics}

Statistical analysis was performed using MINITAB version 14 (Minitab Inc., State College, PA, USA). Means were compared between an ethylene receptor mutant and their wildtype ecotype (Col, No or Ws) using a two-sample t test with a significance level of $\mathrm{P}=0.05$. Data are presented as \% relative to the parent, the results for the wildtype ecotype were set at $100 \%$ and the percentage difference between the ethylene receptor mutants and their corresponding wildtype ecotype is presented.

\section{Results}

\section{Leaf development in ethylene signalling mutants}

It is well documented that exposure of leaf material to ethylene accelerates senescence. In this programme of research the time course of leaf senescence was studied in ethylene perception and signalling mutants in comparison to their wild type (WT) ecotypes. The genotypes studied were three gain of function mutants (etr1, ers2 and ein4) that exhibit insensitivity to the gas as revealed by their inability to exhibit a triple response when exposed to the gas (Table 1), and two loss of function mutants where expression of the gene encoding the ethylene receptor ETR2 or ERS1 (etr2 and ers1) are substantially down-regulated (Alonso and others 2003). Leaf senescence was measured in an individual organ by tagging leaf six from the time of emergence through to end of life and measuring chlorophyll content every six days over a 48 day period (Fig. 1A). To determine a more global senescence profile whole 
rosettes were assessed over the same timeframe (Fig. 1B). Individual leaf 6 of etrl plants exhibited a delayed onset of senescence (Fig. 1A), with chlorophyll sustained in the middle part of leaf development (12-30 days after emergence) and a similar observation was seen in the rosette (Fig. 1B) which remained fully green at least six days longer than the WT and senescence, when it did occur, was primarily noticeable at the leaf tips. Global leaf lifespan was prolonged in the ers 2 mutant (Fig. 1A \& B) and this was conferred by maintenance of chlorophyll in the early stages of leaf life (2-12 days after emergence) although once senescence had been induced this took place faster than the WT (Fig. 1A). The whole rosette of etr2 plants appeared to retain chlorophyll for longer than WT (Fig. 1B), although leaf 6 did not exhibit delayed senescence (Fig. 1A). Individual leaves of the ein4 mutant lost chlorophyll more rapidly than WT plants at the very end of senescence (48 days in Fig. 1B) although the rate of global senescence of the rosette was may have been delayed at the earlier stages in relation to the parental ecotype. Clearly the plants were under stress since they appeared to accumulate anthocyanins overlying the remaining chlorophyll at days 36-42 more than the other mutant genotypes, in line with the anthocyanin accumulation apparent in the WT in the same time period.

\section{Flower and pod development in ethylene signalling mutants}

The time course of development of reproductive structures in Arabidopsis plants was investigated in the different mutants by tagging individual flowers on the main inflorescence and then following them through from petal abscission through to pod dehiscence (Fig. 2). Petals of etrl flowers were retained for almost twice as long as WT flowers and senescence of the pods in this mutant was also delayed and as a consequence the time from flowering to pod shatter of an individual etr1 pod was approximately $40 \%$ longer than in WT plants. ers 2 pods also displayed a significantly extended life span primarily as a consequence of a delay in the final stages of pod senescence although the timing of petal abscission was also somewhat delayed compared to WT. ein4 exhibited similar features to etr2 exhibiting a $10 \%$ extension in pod life span compared to WT primarily as a consequence of a more prolonged period of time spent at S3 when pod senescence was taking place (Fig. 2).

\section{Whole plant development and seed yield in ethylene signalling mutants}

The height of the primary inflorescence is significantly reduced in etrl plants with the stature of the mutant attaining only $60 \%$ of WT plants (Fig. 3A). Furthermore, the lifespan of etrl plants is also substantially curtailed (Fig. 3B). In contrast, ers 1 plants significantly exceed the 
height of their parental WT lines by approximately $10 \%$ (Fig. 3A) but their lifespan was unaffected (Fig. 3B). The height and lifespan of the other mutants studied was indistinguishable from their ecotype controls.

Although it is evident that mutations in ethylene receptor signalling can attenuate the development of leaves, flowers and siliques in Arabidopsis what is even more critical is the impact that these changes have on plant yield. We therefore carried out a detailed analysis of the total seed yield per plant and the individual components that contributes to this parameter. Overall, the mutants etrl, ein 4 , ers 1 , and ers 2 have a significantly deleterious impact on total weight of seed produced per plant compared to WT plants (Fig. 4D). For all 4 mutants the reduction was approximately $40 \%$. Only etr 2 showed a significant increase, of approaching $20 \%$ in total yield of seed (Fig. 4D). Athough the majority of mutants exhibited reduced yield, thousand grain weight (TGW) was significantly higher, by as much as $20 \%$, in ein4, etrl and etr2 (Fig. 4C). These three mutants retained significantly fewer seeds per pod as did both ers 1 and ers 2 albeit to a smaller degree compared to their parental WT lines (Fig. 4A). In general, the mutants produced a similar total number of pods per plant with the exception of ers1 that generated approaching twice as many pods as WT (Fig. 4B).

\section{Discussion}

Although it is well documented that exposure of plants to exogenous ethylene can influence both the timing and rate of organ senescence the role of endogenous levels of the gas in regulating the process in vivo is less well defined (Graham and others 2012). One strategy that has been adopted to explore this phenomenon is to block ethylene action using inhibitors such as 1-MCP (Sisler and Serek 1997) or silver ions (McDaniel and Binder 2012). Whilst these approaches have generated valuable data the impact of inhibitors on other cellular events is always open to question and in this study we have explored the use of ethylene receptor mutants to dissect the role of the gas in regulating Arabidopsis development. In particular we have studied the progression of leaf, flower and pod senescence and correlated these events with seed yield. We have previously shown that senescence in Arabidopsis is regulated in unique ways in these three organs (Wagstaff and others 2009) and that ethylene biosynthesis and binding appeared to be more important in silique and petal senescence than in leaves, although some elements were conserved in all three tissue types examined. The family of Arabidopsis ethylene receptors comprises five members and because of the nature 
of the signalling process mutations in the ethylene binding domain can generate dominant mutants such as etrl, ein4 and ers2 that are blind to the gas (Binder and others 2012). We have studied these three gain of function mutants in detail and also the two loss of function mutants, ers 1 and etr 2 where, due to a T-DNA insertion in the respective genes, we have been able to probe the specific contributions of ERS1 and ETR2 to plant senescence and the results are summarised in Fig 5.

Reports of delayed senescence in ethylene mutants and transgenics generally relate to flower longevity (Jones, 2008) or individual leaf longevity (Grbic and Bleecker, 1995; Wang and Kumar, 2004). Our data show that the senescence pattern of an individual leaf (leaf 6) was changed in etrl, etr 2 and ers 2 mutants. In etr 1 and ers 2 this also resulted in delayed senescence of the entire rosette, but this was not the case for etr 2 which began the onset of senescence at a similar time to the WT plants but the rate of senescence was reduced. There is a question of how functional the observed leaf 'stay-green' phenotypes are since extended leaf longevity is not necessarily related to plant longevity suggesting that photosynthates are not available for remobilization, supporting evidence from Grbic and Bleecker (1995) that leaves functionally senesced even though the apparent life span of the leaf was prolonged. Re-allocation of resources around the plant did not always occur in proportion to the photosynthetic period; ers 2 maintained leaf chlorophyll at a time when senescence in the WT had started, but senescence occurred extremely rapidly in the mutant once it was triggered.

There is a substantial body of evidence that ethylene can accelerate the onset of flower abscission although the gas is not critical for organ shedding to take place (Roberts and others 2002). In accord with these observations and reports by others (Patterson and Bleecker 2004) whilst the timing of petal abscission was delayed in etrl plants shedding ultimately took place. It has previously been shown that the introduction of the mutated version of ETR1 into other species can delay both flower senescence and abscission (Yang and others 2008). Interestingly the timing of shedding in ein4, that has also been classified as ethylene insensitive on the basis of its inability to undergo the triple response, was indistinguishable from WT. This observation provides clear evidence that the different receptor family members have different signaling capacities and that conclusions about the roles of ethylene in a particular developmental process based on the phenotypes of individual mutants should be interpreted with caution.

Pods from ers 2 plants underwent shatter significantly later than WT primarily as a consequence of the final stages of senescence being prolonged. Pod dehiscence is an important event in the regulation of yield in species such as Brassica napus (Roberts and 
others 2002) and this observation may be of value in identifying strategies to reduce premature shatter. A slower rate of pod senescence was observed in both etr 2 and ein 4 plants which spent longer at stage 3, mimicking the pattern observed in individual leaves, but the total reproductive period was not extended in either genotype. In etrl the longevity of individual flowers and pods was also increased, but the reproductive period was significantly shorter than WT. In contrast to leaves, it would appear that in etrl, etr2 and ein 4 the extended pod green period is potentially functional, or that resource partitioning was affected by the mutations, since there was a significant increase in TGW, but overall seed yield was reduced due to fewer seeds per pod. These data support an important role for local photosynthesis of the pod in seed filling. The RNAi-driven down-regulation of ETR2 in rice has also been reported to increase TGW but overall plant seed yield or seeds per panicle was not recorded (Wuriyanghan and others 2009). The same authors reported an early onset of flowering in the rice etr2 mutants, suggesting that the life cycle was accelerated; in our hands the only Arabidopsis mutant with an accelerated life cycle was etrl. The curtailed life span in etrl plants correlates with both a significantly reduced plant height and a small reduction in total number of pods. This indicates that ethylene signaling through ETR1 is important to maintain the 'normal' developmental sequence in Arabidopsis and a failure to achieve this results in a substantial decline in seed yield.

The ers 1 mutant produces more pods and is taller, thereby making more reproductive positions available during its life cycle compared to the WT. Although the mutant produces a similar number of seeds per pod as WT both TGW and total yield is reduced indicating that the seed content is reduced. Previous studies have shown that ethylene-insensitive mutants of Arabidopsis exhibit poor germination in relation to the WT (Bleecker and others 1988), perhaps indicating a reduction of available assimilates, and conversely the over-producing mutant etol has accelerated germination (Cheng and others 2009). Global reproductive lifespan is unaffected in ein 4 , but TGW is increased compared to WT which was shown to be achieved through investing in fewer, heavier seeds per pod although the absolute mass of seeds per plant was reduced. Like etrl, ers 2 has a foreshortened period where the pod is fully photosynthetic but this is compensated for by spending longer in the late stages of pod development. Plant overall seed yield in ers2 is also reduced but there is no change in TGW, indicating that the late produced seeds are less well filled. The etr 2 mutant maintains seed filling throughout the reproductive lifespan, resulting in an increased TGW and overall plant seed yield of nearly $20 \%$ above WT values in both cases. 
A possible mechanism to explain the organ-specific differences observed between the different mutants was first proposed by Klee (2004) who suggested that the concentration of receptors varies between tissues, enabling the plant to have differential temporal and spatial sensitivity to ethylene. Receptors are also known to form dimer complexes (Liu and Wen, 2012); thus mutating one half of a dimer could impact on the function of the other partner in the complex and make teasing apart the functions of individual genes rather more difficult, but also provides a tool by which ethylene responses can be repressed to different extents. The results presented in this paper clearly support a role for individual family members to contribute to the perception of ethylene at different developmental stages and supports the hypothesis that responses may be tissue specific as asserted by Shakeel and others (2013). Others have noted unique roles for particular isoforms; ETRl has long been associated with delayed leaf senescence and larger leaves (Grbić and Bleeker, 1995), but more recently has been shown to be required for nutation of seedlings (Binder and others, 2006). ETR2 is essential for correct trichome branching, which is controlled by microtubule assembly (Plett and others, 2009). ETR1, ETR2 and EIN4 are all important for growth recovery following exposure to ethylene (Binder and others, 2004), however the ers 1 mutant appears to cause growth inhibition in low ethylene environments (Liu and others, 2010); in the present study we showed that this is not necessarily correlated with low yield.

The controlled induction of mutant ethylene signalling phenotypes could have implications for crop production in the future. Maintenance of green leaf colour in transgenic coriander using the mutated version of the ERS1 gene has already been shown to be beneficial for the production of leafy crops (Wang and Kumar 2004) and transformation of tomatoes with an inducible version of the ethylene insensitive ETRl gene provides a strategy for regulating fruit ripening (Gallie 2010). Our observations indicate that the timing and duration of organ senescence can be manipulated by attenuating ethylene perception and signaling and that this could enhance leaf, flower and pod longevity and have consequences for seed quantity and possibly quality. Further work will be necessary to develop a strategy in individual crop species that might lead to beneficial phenotypes for both the producer and consumer.

\section{Acknowledgements}

EB would like to thank Tozer Seeds, the University of Nottingham, and the University of Reading Endowment Trust Fund for funding her $\mathrm{PhD}$. 


\section{References}

Abeles FB, Morgan PW, Saltveit ME (1992) Ethylene in plant biology. 2nd ed. Academic Press, San Diego

Agarwal G, Choudhary D, Singh VP, Arora A (2012) Role of ethylene receptors during senescence and ripening in horticultural crops. Plant Signal Behav 7:827-846

Alonso JM, Stepanova AN, Leisse TJ, Kim CJ, Chen H, Shinn P, Stevenson

DK, Zimmerman J, Barajas P, Cheuk R, Gadrinab C, Heller C, Jeske A, Koesema E, Meyers

CC, Parker H, Prednis L, Ansari Y, Choy N, Deen H, Geralt M, Hazari N, Hom E, Karnes

M, Mulholland C, Ndubaku R, Schmidt I, Guzman P, Aguilar-Henonin L, Schmid M, Weigel

D, Carter DE, Marchand T, Risseeuw E, Brogden D, Zeko A, Crosby WL, Berry CC, Ecker JR (2003) Genome-wide insertional mutagenesis of Arabidopsis thaliana. Science 301:653657

Bennett E, Roberts JA, Wagstaff C (2012) Manipulating resource allocation in plants. J Exp Bot 63:3391-3400

Binder BM, O'Malley RC, Wang W, Moore JM, Parks BM, Spalding EP, Bleecker AB (2004) Arabidopsis Seedling Growth Response and Recovery to Ethylene. A Kinetic Analysis. Plant Physiol 136: 2913-2920

Binder BM, Chang C, Schaller EG (2012) Perception of ethylene by plants - ethylene receptors. Annual Plant Reviews Volume 44: The Plant Hormone Ethylene. WileyBlackwell, Oxford, UK pp117-146

Binder BM, O'Malley RC, Wang W, Zutz TC, Bleecker AB (2006)

Ethylene stimulates nutations that are dependent on the ETR1 receptor. Plant Physiol 42:1690-1700

Binder BM, Rodríguez FI, Bleecker AB (2010) The copper transporter RAN1 is essential for biogenesis of ethylene receptors in Arabidopsis. J Biol Chem 285:37263-37270

Bisson MM, Groth G (2010) New insight in ethylene signalling: autokinase activity of ETR1 modulates the interaction of receptors and EIN2. Mol Plant 3:882-889

Bleecker AB, Estelle MA, Somerville C, Kende H (1988)

Insensitivity to ethylene conferred by a dominant mutation in Arabidopsis thaliana.Science 241:1086-1090

Bleecker AB, Kende H (2000) Ethylene: a gaseous signal molecule in plants. Annu Rev Cell Dev Bio 16:1-18 
Buchanan-Wollaston V (1997) The molecular biology of leaf senescence. J Exp Bot 48:181199

Cancel JD, Larsen PB (2002) Loss-of-function mutations in the ethylene receptor ETR1 cause enhanced sensitivity and exaggerated response to ethylene in Arabidopsis. Plant Physiol 129:1557-1567

Carbonell-Bejerano P, Urbez C, Granell A, Carbonell J, Perez-Amador MA (2011)

Ethylene is involved in pistil fate by modulating the onset of ovule senescence and the GAmediated fruit set in Arabidopsis. BMC Plant Biol 11:84

Chang C, Kwok SF, Bleecker AB, Meyerowitz EM (1993) Arabidopsis ethylene response gene ETR1: similarity of product to two-component regulators. Science 262:539-544 Cheng W-H, Chiang M-H, Hwang S-G and Lin P-C (2009) Antagonism between abscisic acid and ethylene in Arabidopsis acts in parallel with the reciprocal regulation of their metabolism and signaling pathways. Plant Mol Biol 71: 61-80

Desikan R, Hancock JT, Bright J, Harrison J, Weir I, Hooley R, Neill SJ (2005) A role for ETR1 in hydrogen peroxide signaling in stomatal guard cells. Plant Physiol 137:831-834 Gallie DR (2010) Regulated ethylene insensitivity through the inducible expression of the Arabidopsis etr1-1mutant ethylene receptor in tomato. Plant Physiol 152:1928-1939 Gallie DR, Young TE (2004) The ethylene biosynthetic and perception machinery is differentially expressed during endosperm and embryo development in maize. Mol Genet Genomics 271:267-281

Gamble RL, Qu X, Schaller GE (2002) Mutational analysis of the ethylene receptor ETR1. Role of the histidine kinase domain in dominant ethylene insensitivity. Plant Physiol 128:1428-1438

Gao Z, Chen YF, Randlett MD, Zhao XC, Findell JL, Kieber JJ, Schaller GE (2003) Localization of the Raf-like kinase CTR1 to the endoplasmic reticulum of Arabidopsis through participation in ethylene receptor signaling complexes. J Biol Chem 278: 34725-34732

Gao Z, Wen CK, Binder BM, Chen YF, Chang J, Chiang YH, Kerris RJ, Chang C, Schaller GE (2008) Heteromeric interactions among ethylene receptors mediate signalling in Arabidopsis. J Biol Chem 283: 23801-23810

GrahamLE, Schippers JHM, Dijkwel PP, Wagstaff C (2012) Ethylene and senescence processes. Annual Plant Reviews Volume 44: The Plant Hormone Ethylene. WileyBlackwell, Oxford, UK pp 305-341 
Grbić, V, Bleecker, AB (1995) Ethylene regulates the timing of leaf senescence in Arabidopsis. Plant J 8: 595-602

Grefen C, Städele K, Růzicka K, Obrdlik P, Harter K, Horák J (2008)

Subcellular localization and in vivo interactions of the Arabidopsis thaliana ethylene receptor family members. Mol Plant 1:308-320

Guo H, Ecker JR (2004) The ethylene signaling pathway: new insights. Curr Opin Plant Biol $7: 40-49$

Hall BP, Shakeel SN, Amir M, Ul Haq N, Qu X, Schaller GE (2012)

Histidine kinase activity of the ethylene receptor ETR1 facilitates the ethylene response in Arabidopsis. 159:682-695

Hassan FAS, Mahfouz SA (2010) Effect of 1-methylcyclopropene (1-MCP) treatment on sweet basil leaf senescence and ethylene production during shelf-life. Postharvest Biol Technol 55:61-65

Hensel LL, Grbić V, Baumgarten DA, Bleecker AB (1993) Developmental and age-related processes that

influence the longevity and senescence ofphotosynthetic tissues in Arabidopsis. Plant Cell $5: 553-564$

Hua J, Chang C, Sun Q, Meyerowitz EM (1995) Ethylene insensitivity conferred by Arabidopsis ERS gene. Science 269:1712-1714

Jing HC, Schippers JH, Hille J, Dijkwel PP (2005) Ethylene-induced leaf senescence depends on age-related changes and OLD genes in Arabidopsis. J Exp Bot 56:2915-2923

Jing HC, Sturre MJ, Hille J, Dijkwel PP (2002) Arabidopsis onset of leaf death mutants identify a regulatory pathway controlling leaf senescence. Plant J 32:51-63

Jones ML (2008) Ethylene signaling is required for pollination-accelerated corolla senescence in petunias. Plant Science 175:190-196

Ju C, Chang C (2012) Advances in ethylene signalling: protein complexes at the endoplasmic reticulum membrane. AoB Plants pls031

Klee HJ (2004) Ethylene signal transduction. Moving beyond Arabidopsis. Plant Physiol $135: 660-667$

Kou X, Watkins CB, Gan SS (2012) Arabidopsis AtNAP regulates fruit senescence. J Exp Bot 63:6139-6147

Liu Q, Xu C, Wen C-K (2010) Genetic and transformation studies reveal negative regulation of ERS1 ethylene receptor signaling in Arabidopsis. BMC Plant Biology 10:60 
Liu Q, Wen CK (2012) Arabidopsis ETR1 and ERS1 differentially repress the ethylene response in combination with other ethylene receptor genes. Plant Physiol 158:1193-1207 Ma QH, Wang XM (2003) Characterization of an ethylene receptor homologue from wheat and its expression during leaf senescence. J Exp Bot 54:1489-1490 McDaniel BK, Binder BM (2012) ETHYLENE RECPTOR1 (ETR1) is sufficient and has the predominant role in mediating inhibition of ethylene responses by silver in Arabidopsis thaliana. J Biol Chem 287:26094-26103

Neljubov D (1901) Uber die horizontale nutation der stengel von Pisum sativum und einiger anderer. Pflanzen Beitrage und Botanik Zentralblatt 10: 128-139

O'Malley RC, Rodriguez FI, Esch JJ, Binder BM, O'Donnell P, Klee HJ, Bleecker AB (2005) Ethylene-binding activity, gene expression levels, and receptor system output for ethylene receptor family members from Arabidopsis and tomato. Plant J 41:651-659

Patterson SE, Bleecker AB (2004) Ethylene-dependent and -independent process associated with floral organ abscission in Arabidopsis. Plant Physiol 134:194-203

Plett JM, Mathur J, Regan S (2009) Ethylene receptor ETR2 controls trichome branching by regulating microtubule assembly in Arabidopsis thaliana. J Exp Bot 60: 3923-3933 Qu X, Hall BP, Gao Z, Schaller GE (2007) A strong constitutive ethylene-response phenotype conferred on Arabidopsis plants containing null mutations in the ethylene receptors ETR1 and ERS1. BMC Plant Biol 7:3

R Core Team (2013) R: A language and environment for statistical computing. R Foundation for Statistical Computing, Vienna, Austria. URL http://www.R-project.org/

Robert C, Noriega A, Tocino A, Cervantes E (2008) J Plant Physiol Morphological analysis of seed shape in Arabidopsis thaliana reveals altered polarity in mutants of the ethylene signaling pathway. 165:911-919

Roberts JA, Elliott KA, Gonzalez-Carranza Z (2002) Abscission, dehiscence, and other cell separation processes. Ann Rev Plant Biol 53:131-58

Rodríguez FI, Esch JJ, Hall AE, Binder BM, Schaller GE, Bleecker AB (1999) A copper cofactor for the ethylene receptor ETR1 from Arabidopsis. Science 283:996-998

Sakai H, Hua J, Chen QG, Chang C, Medrano LJ, Bleecker AB, Meyerowitz EM (1998) ETR2 is an ETR1-like gene involved in ethylene signaling in Arabidopsis. Proc Natl Acad Sci U S A 95:5812-5817

Serek M, Woltering EJ, Sisler EC, Frello S, Sriskandarajah S (2006) Controlling ethylene responses in flowers at the receptor level. Biotechnol Adv 24:368-381 
Shakeel SN, Wang X, Binder BM, Schaller GE (2013) Mechanisms of signal transduction by ethylene: overlapping and non-overlapping signalling roles in a receptor family. AoB Plants 5:plt010

Sisler EC, Serek M (1997) Inhibitors of ethylene responses in plants at the receptor level: Recent developments. Physiol Plantarum 100: 577-582

Thomas H, Howarth CJ (2000) Five ways to stay green. J Exp Bot 52:329-337

Wagstaff C, Yang TJ, Stead AD, Buchanan-Wollaston V, Roberts JA (2009) A molecular and structural characterization of senescing Arabidopsis siliques and comparison of transcriptional profiles with senescing petals and leaves. Plant J 57:690-705

Wang Y, Kumar PP (2004) Heterologous expression of Arabidopsis ERS1 causes delayed senescence in coriander. Plant Cell Rep 22:678-683

Wellburn AR (1994) The spectral determination of chlorophyll a and chlorophyll b, as well as total carotenoids, using various solvents with spectrophotometers of different resolution. $\mathbf{J}$ Plant Physiol 144:307-313

Wuriyanghan H, Zhang B, Cao WH, Ma B, Lei G, Liu YF, Wei W, Wu HJ, Chen LJ, Chen HW, Cao YR, He SJ, Zhang WK, Wang XJ, Chen SY, Zhang JS (2009) The ethylene receptor ETR2 delays floral transition and affects starch accumulation in rice. Plant Cell 21:1473-1494

Yang J, Zhang J, Wang Z, Liu K, Wang P (2006) Post-anthesis development of inferior and superior spikelets in rice in relation to abscisic acid and ethylene. J Exp Bot 57:149-160 Yang T, Gonzalez-Carranza ZH, Maunders M, Roberts JA (2008) Ethylene and the regulation of senescence processes in transgenic Nicotiana sylvestris plants. Ann Bot 101:301-10 
Figure legends

\section{Figure 1}

Leaf chlorophyll content during lifespan. (A) Chlorophyll content of leaf 6 from time of emergence until full senescence $(n=3)$. Wild type lines are shown next to the relevant mutants. (B) shows rosette leaf senescence in the mutants compared to the wild type plants. (G) indicates a gain of function mutant; (L) indicates a loss-of-function mutant. Parental ecotypes are indicated as follows: Columbia-0 (Col), Wassilewskija (Ws) and Nossen (No).

\section{Figure 2}

Ethylene mutant reproductive development time course. Time spent at each stage of development is shown with anthesis taken as time zero. Pod stage $1=$ Pods are green and fully mature, pod stage $2=$ pods are $50 \%$ yellow, pod stage $3=$ pods are $100 \%$ yellow, pods stage 4 = pods are brown and just about to dehisce, $n=16$. Bars represent the mean $\pm S E$ and those which are statistically significant from their parent line (Col, No or Ws) are indicated by an asterisk, $* \mathrm{P}<0.05, * * \mathrm{P}<0.01, * * * \mathrm{P}<0.001$. (G) indicates a gain of function mutant; (L) indicates a loss-of-function mutant.

\section{Figure 3}

Whole plant development (A) Height of the primary inflorescence compared to the relevant WT plant (B) Reproductive lifespan; time from bolt emergence to the end of pod senescence. Bars indicate $S E M$ from $n=5$. Asterisks indicate lines which are significantly different from their parent line (Col, No or Ws), $* \mathrm{P}<0.05, * * \mathrm{P}<0.01, * * * \mathrm{P}<0.001$. (G) indicates a gain of function mutant; (L) indicates a loss-of-function mutant.

\section{Figure 4}

Yield parameters from ethylene mutants.(A) Number of seeds per pod (B) Number of pods per plant (C) Thousand Grain Weight (D) Total mass of seed yield per plant. All values are expressed as a $\%$ of the relevant WT line with the original units of measurement indicated on the $y$ axis. Bars indicate SEM from $n=5$. Asterisks indicate lines which are significantly different from their parent line (Col, No or $\mathrm{Ws}), * \mathrm{P}<0.05$, ** $\mathrm{P}<0.01$, *** $\mathrm{P}<0.001$. (G) indicates a gain of function mutant; (L) indicates a loss-of-function mutant.

\section{Figure 5}

Interactions between developmental and yield parameters. Key to figure as follows: (ND) No sig difference from parent; ( --- $)^{* * *}$ sig difference from parent in minus direction; ( -- )** sig difference from parent in minus direction; $(-)^{*}$ sig difference from parent in minus direction; $(+++) * * *$ sig difference from parent in positive direction; $(++) * *$ sig difference 
from parent in positive direction; $(+) *$ sig difference from parent in positive direction. Blue shading indicates a negative interaction, red shading indicates a positive interaction.

\section{Table 1}

Ethylene receptor mutants used in the study along with their corresponding backgrounds and location of the mutation. 